\title{
Interactive Multimedia Services Research, Used in the Systems Engineering Career of the Technological Institute of Mexicali
}

\author{
PhD Jesús Francisco Gutiérrez Ocampo \\ M.C. Corina Araceli Ortiz Pérez \\ M.C. José Antonio Camaño Quevedo \\ Karla Jasmin Castelo Zamora \\ Andrea Valdez Yañez \\ Instituto Tecnologico de Mexicali
}

\begin{abstract}
This quantitative research, has the objective of measuring the impact on the users of Interactive multimedia services, in the systems engineering career of the Instituto Tecnológico de Mexicali. The method is a survey applied to a sample of students of the Systems Engineering degree at the Instituto Tecnológico de Mexicali. The results of a survey applied about Interactive multimedia services is Interactive multimedia services, is a new tool of the Acrobat DC professional suite, which allows the user to generate PDF documents which contain various multimedia elements, such as MP3 audios, Videos, Photos, which are intended to be a valuable tool in the student teaching process and is used successful for the 402 students enrolled in systems engineering career of the Instituto Tecnológico de Mexicali. Based on the results obtained from this research, it can be seen that the students of the systems engineering career of the Technological Institute of Mexicali, consider themselves to be enthusiastic about information and communication technologies, such as interactive multimedia services, and they wish to use these technologies, as an area of opportunity we discovered that this technology is not currently used in the systems engineering career of the Technological Institute of Mexicali, nor in other academic departments, the students surveyed show that they know these technologies and that they would recommend them as a means to improve the learning, besides that they consider these technologies reliable.
\end{abstract}

Keywords: Interactive Multimedia Services, PDF Multimedia, Systems Engineering 


\section{Introduction}

Interactive multimedia services, is a new tool of the Acrobat DC professional suite, which allows the user to generate PDF documents which contain various multimedia elements, such as MP3, Videos, Photos, which are intended to be a tool valuable in the teaching learning process of students, this quantitative research has the objective of measuring the impact on users of the systems engineering career of the Technological Institute of Mexicali, which has 402 students enrolled and make a diagnosis, based on the results of a survey applied to a sample of students from the systems engineering career of the Technological Institute of Mexicali.

\section{Instrument Used}

1. The Interactive Multimedia Services that are used in the subjects of the Computer Systems Engineering career at the Technological Institute of Mexicali, are known by the students.

2. The Interactive Multimedia Services that are used in the subjects of the Computer Systems Engineering career at the Technological Institute of Mexicali, are useful for the student.

3. The Interactive Multimedia Services that are used in the subjects of the Computer Systems Engineering career at the Technological Institute of Mexicali, are used regularly in classes.

4. The Interactive Multimedia Services that are used in the subjects of the Computer Systems Engineering career at the Technological Institute of Mexicali, would recommend them to other students.

5. The Interactive Multimedia Services that are used in the subjects of the Computer Systems Engineering career at the Technological Institute of Mexicali, you consider them necessary for a better learning.

6. The Interactive Multimedia Services that are used in the subjects of the Computer Systems Engineering career at the Technological Institute of Mexicali. Apart from the use in class, you have seen them used in some other department of the ITM.

7. The Interactive Multimedia Services that are used in the subjects of the Computer Systems Engineering career at the Technological Institute of Mexicali. In the last 12 months you have used them in the ITM.

8. The Interactive Multimedia Services that are used in the subjects of the Computer Systems Engineering career at the Technological Institute of Mexicali. If you had the opportunity to use this technology, you would use it.

9. The Interactive Multimedia Services that are used in the subjects of the Computer Systems Engineering career at the Technological Institute of Mexicali, 
you consider them reliable for use in the classroom.

10. As a student of the subjects of the Computer Systems Engineering career at the Technological Institute of Mexicali, you consider yourself an enthusiast of information technologies.

With the following multiple choice answers:

a. Totally disagree

b. Disagree

c. A little disagree

d. A little bit of agreement

e. Agree

f. Totally agree

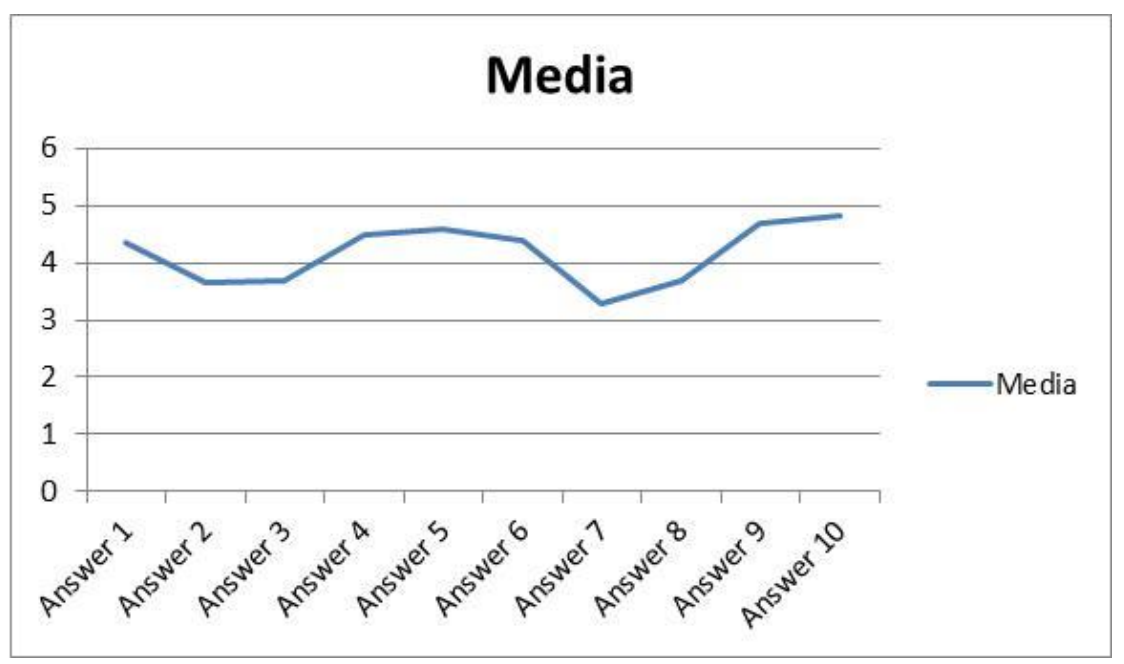

Fig. 1. Graph of results.

\section{Conclusions}

Based on the results obtained from this research, it can be seen that the students of the systems engineering career of the Technological Institute of Mexicali, consider themselves to be enthusiastic about information and communication technologies, such as interactive multimedia services, and they wish to use these technologies, as an area of opportunity we discovered that this technology is not currently used in the systems engineering career of the Technological Institute of Mexicali, nor in other academic departments, the students surveyed show that they know these technologies and that they would recommend them as a means to improve the learning, besides that they consider these technologies reliable. 


\section{References}

[1] Lisa Fridsma. (2015). Adobe Acrobat DC Classroom in a Book. usa: adobe press.

[2] Lon Safko. (2010). The Social Media Bible: Tactics, Tools, and Strategies for Business Success. USA: wiley.

[3] Harry Hemus. (2015). DIVIDI Projects. 20/08/2017, de DIVIDI PROJECTS Sitio web: http://www.dividiprojects.com/

[4] Michael Porter. (1983). Cases in Competitive Strategy. usa: the free press.

[5] Measuring the Sustainability of Protected Area-Based Tourism Systems: A Multimethod Approach Poudel, Surya, 2014

[6] Addressing Sustainability in an Entrepreneurship Ecosystem: A Case Study of a Social Incubator in Mexico Wood, Mark Williams, 2014

[7] Developing green management standards for restaurants: An application of green supply chain management Yao-Fen Wanga, Su-Ping Chenb, Yi-Ching Leea, Chen-Tsang (Simon) Tsaia, 2013

[8] Environmental sustainability of service supply chains: Contract design and evidence on operating performance in the U.S. hospitality industry Zhang, Jie, 2011 